Check for updates

Cite this: RSC Adv., 2018, 8, 11828

\title{
Green emission of indium oxide via hydrogen treatment $\uparrow$
}

\author{
Syeda Arooj, TingTing Xu, Xudong Hou, Yang Wang, Jing Tong, Runrun Chu \\ and Bo Liu (D) *
}

In this work, we prepared hydrogen treated indium oxide $\left(\mathrm{H}_{2}-\mathrm{In}_{2} \mathrm{O}_{3}\right)$ and investigated the effect of hydrogen treatment on the optical and photoluminescence properties of $\ln _{2} \mathrm{O}_{3}$. Hydrogen treatment has no influence on the crystal structure, but alters the intrinsic electronic structure and optical properties via introducing hydrogen induced defects such as shallow donor states (near the conduction band) and singly ionized oxygen vacancies in $\mathrm{H}_{2}-\mathrm{In}_{2} \mathrm{O}_{3}$. Both air- $\mathrm{In}_{2} \mathrm{O}_{3}$ (air calcinated) and $\mathrm{H}_{2}-\mathrm{In}_{2} \mathrm{O}_{3}$ show intense blue emission under UV excitation (280 nm). However, hydrogen treated $\mathrm{In}_{2} \mathrm{O}_{3}$ exhibited an additional green emission, which is absent in air- $\ln _{2} \mathrm{O}_{3}$. This green emission arises from the passivation of singly ionized oxygen vacancies by hydrogen treatment. Hydrogen treatment could be a promising strategy to tune the electronic and optical properties of $\mathrm{In}_{2} \mathrm{O}_{3}$.

Received 22nd January 2018

Accepted 18th March 2018

DOI: $10.1039 / \mathrm{c} 8 \mathrm{ra00654g}$

rsc.li/rsc-advances

include indium vacancy, oxygen vacancy, indium interstitials, oxygen interstitials, staking faults, etc. However, the exact photo-luminescence emission mechanism is still controversial. ${ }^{20-22}$ As mentioned above, studies on optical and especially luminescence properties of $\operatorname{In}_{2} \mathrm{O}_{3}$ mainly focused on shape and size dependent micro/nanostructures. ${ }^{12,18}$ In general, there is no universally accepted PL mechanism. Hence, investigation on the luminescence mechanism of the visible PL in $\operatorname{In}_{2} \mathrm{O}_{3}$ is still necessary. Herein, we explored hydrogen induced defects and their effects on luminescence properties of $\operatorname{In}_{2} \mathrm{O}_{3}$ nanoparticles.

Hydrogen induced alteration in metal oxide structures has been a topic of substantial interest, because hydrogen treatment plays a vital role in tailoring the optical, photocatalytical and electronic properties of metal oxides. ${ }^{23-25}$ The intentional or unintentional doping of metal oxides with hydrogen exhibits different behaviors depending on the host matrix. Chen et al. reported the synthesis of disorder-engineered black $\mathrm{TiO}_{2} \cdot{ }^{26} \mathrm{By}$ the help of hydrogen treatment they introduced disorders in $\mathrm{TiO}_{2}$ nano-crystals. Hydrogen treatment created lattice disorders and generated mid gap states. For instance, instead of forming donor states near conduction band (CB), these mid gaps produced extending energy levels and formed band tail states. The extended energy states became dominant centres for optical excitation and relaxation processes. An additional advantage of engineered disorder was that they provided trapping sites for photo-induced carriers and prevented the rapid recombination process. Hydrogen treatment affected possible electron transfer, photocatalytic process, optical, and luminescent properties of host matrix. ${ }^{27,28}$ Ting et al. demonstrated the defect-based photoluminescence (PL) efficiency of colloidal $\mathrm{Y}^{-}-\mathrm{Ga}_{2} \mathrm{O}_{3}$ nanocrystals. ${ }^{29}$ Reducing environment $\left(\mathrm{H}_{2} / \mathrm{Ar}\right)$ increased the concentration of Department of Chemistry, University of Science and Technology of China, Hefei, Anhu 230026, P. R. China. E-mail: liuchem@ustc.edu.cn

$\dagger$ Electronic supplementary information (ESI) available. See DOI: oxygen vacancies and enhanced the photoluminescence 
intensity. On the other hand, blue emission was suppressed in oxidative condition $\left(\mathrm{O}_{2} / \mathrm{Ar}\right)$. The enhancement of UV emission with the help of hydrogen treatment in zinc oxide ( $\mathrm{ZnO}$ ) was earlier reported..$^{30,31}$

Previous reports have suggested that hydrogen donated electrons to the host material and created polaron-like defect. $^{32,33} \mathrm{H}_{2}-\mathrm{In}_{2} \mathrm{O}_{3}$ has been regarded as an excellent transparent conductor than most commonly used $\mathrm{Sn}$ doped $\mathrm{In}_{2} \mathrm{O}_{3}{ }^{28}$ Surprisingly, despite its potential impact as a donor dopant, research studies about the effect of hydrogen on optoelectronic performance of indium oxide are rarely reported. ${ }^{34}$

In present study, hydrogen treatment is used to generate defects in $\mathrm{In}_{2} \mathrm{O}_{3}$. We observed distinct fluorescent emission (green-yellow) for $\mathrm{H}_{2}-\mathrm{In}_{2} \mathrm{O}_{3}$ (grey-coloured sample) under UV excitation. Aiming to clarify the fluorescent emission of $\mathrm{H}_{2}-\mathrm{In}_{2} \mathrm{O}_{3}$, its structural, optical and electronic properties are investigated by using a combination of spectroscopic characterization. This study provide a proper insight into hydrogen induced defect structures and probe the nature of donor states and singly ionized oxygen vacancies and their specific role (shallow donor and passivation behavior) in visible emission over $\operatorname{In}_{2} \mathrm{O}_{3}$ sample.

\section{Results and discussion}

Powder X-ray diffraction (PXRD) patterns of air- $\mathrm{In}_{2} \mathrm{O}_{3}$ and $\mathrm{H}_{2}$ $\mathrm{In}_{2} \mathrm{O}_{3}$ are presented in Fig. 1(a). All diffraction peaks of both samples can be assigned to cubic phase of $\operatorname{In}_{2} \mathrm{O}_{3}$ with space group Ia3. ${ }^{10}$ The intense XRD diffraction peaks at $2 \theta$ values of $21.4,30.5,35.4,50.9$ and $60.6^{\circ}$ could be indexed to (211), (222), (400), (440) and (622) crystal planes of $\operatorname{In}_{2} \mathrm{O}_{3}$, revealing their phase-pure cubic $\operatorname{In}_{2} \mathrm{O}_{3}$ nature. ${ }^{35}$ The diffraction peak of (222) planes is used to estimate crystalline size of both samples by using Debye-Scherrer relation $(D=0.9 \lambda / \beta \cos \theta)$. The crystalline sizes are calculated to be 43 and $33 \mathrm{~nm}$ for air- $\operatorname{In}_{2} \mathrm{O}_{3}$ and $\mathrm{H}_{2}$ $\mathrm{In}_{2} \mathrm{O}_{3}$, respectively. After hydrogen treatment smaller crystalline size suggested that some disordered phase is likely formed in $\mathrm{H}_{2}$ $\mathrm{In}_{2} \mathrm{O}_{3} \cdot{ }^{36}$ In addition, intense PXRD peaks further indicated high crystalline nature of both samples. No characteristic peaks of any other impurities or phases are observed, indicating high purity of both samples. SEM measurements were employed to investigate the morphologies of air- and $\mathrm{H}_{2}-\mathrm{In}_{2} \mathrm{O}_{3}$ nanoparticles. The SEM images of synthesized samples at different (low- and high) magnifications are displayed in Fig. 1b and c. SEM images of both samples disclose the presence of agglomerated structure from tiny uniform-sized sphere-shaped particles. The aggregation is likely due to the heating effect in air and hydrogen atmosphere.

It is obvious that hydrogen treatment does not alter the crystallinity and morphology in comparison with air-annealed $\mathrm{In}_{2} \mathrm{O}_{3}$ judged from PXRD and SEM data. However, surface elemental compositions of air- and $\mathrm{H}_{2}-\mathrm{In}_{2} \mathrm{O}_{3}$ are also studied via XPS analysis. Only $\mathrm{O}$, In and $\mathrm{C}$ (used as reference) signals appear in XPS survey acquired from air- and $\mathrm{H}_{2}-\mathrm{In}_{2} \mathrm{O}_{3}$ (Fig. S2 $\dagger$ ). Furthermore, In $3 \mathrm{~d}$ and $\mathrm{O} 1 \mathrm{~s}$ regions evidenced no significant differences in the particle surface of air- and $\mathrm{H}_{2}-\mathrm{In}_{2} \mathrm{O}_{3}$ (see Fig. S2(b-d) of ESI $\dagger$ ).

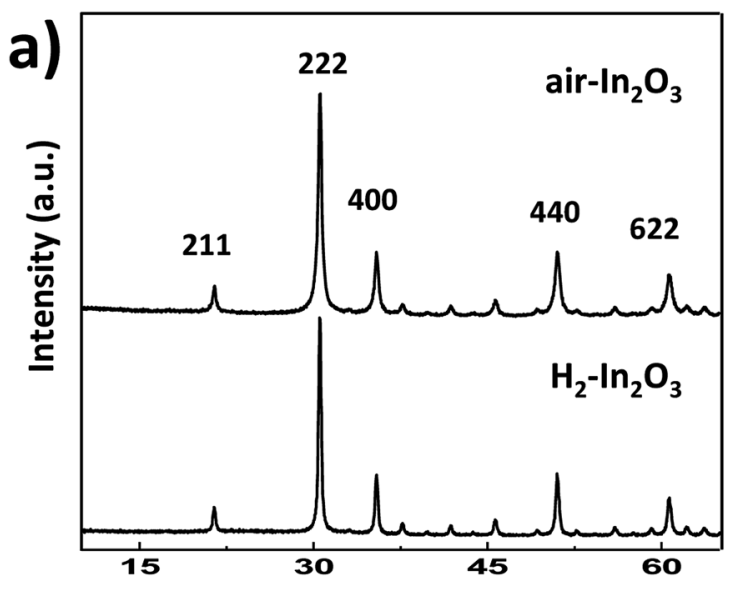

$2 \theta$ (degree)
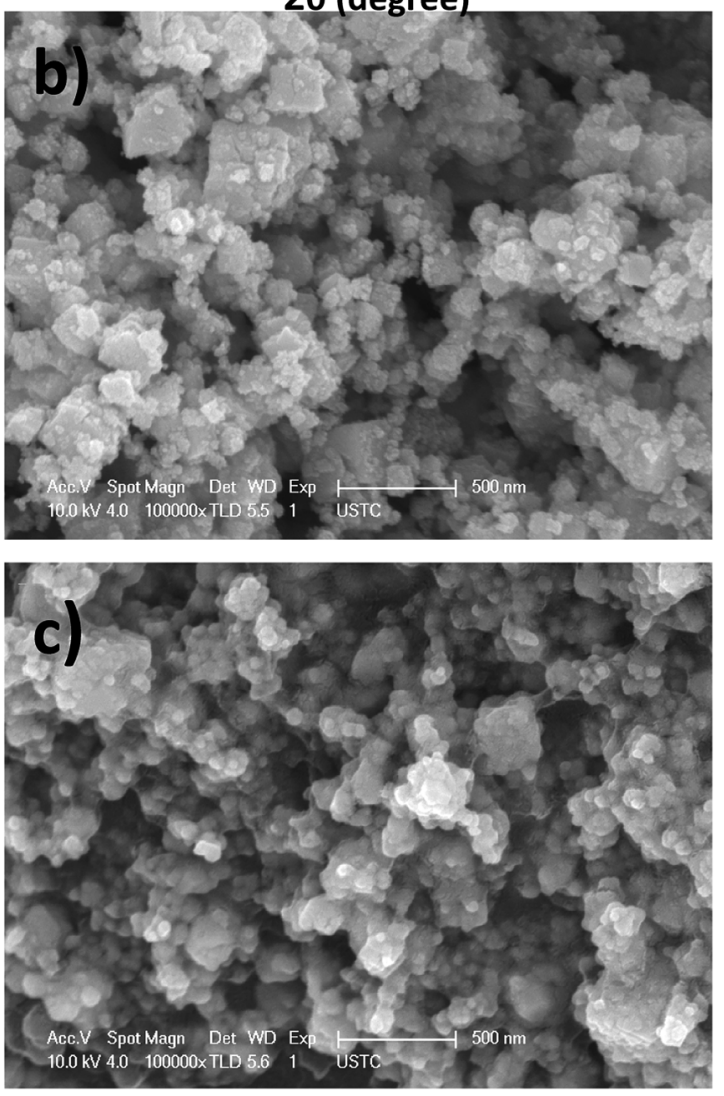

Fig. 1 PXRD patterns of air- and $\mathrm{H}_{2}-\mathrm{In}_{2} \mathrm{O}_{3}$ samples (a). SEM images of air- $\ln _{2} \mathrm{O}_{3}$ (b) and $\mathrm{H}_{2}-\ln _{2} \mathrm{O}_{3}$ (c).

The optical response of hydrogen treated $\operatorname{In}_{2} \mathrm{O}_{3}$ compared to that of air annealed $\operatorname{In}_{2} \mathrm{O}_{3}$ is shown in Fig. 2a. It can be clearly seen that $\mathrm{H}_{2}-\mathrm{In}_{2} \mathrm{O}_{3}$ displays grey colour and a wide absorption in visible light region. The large absorption tail (occurring in visible to IR regions) reveals indisputable evidence that hydrogen treatment induced a large number of oxygen vacancy defects in $\mathrm{H}_{2}-\mathrm{In}_{2} \mathrm{O}_{3} \cdot{ }^{37}$ Electronic transitions from valence band (VB) to the localized states, and from these isolated states to conduction band (CB), are responsible for the VIS-NIR absorption $(\lambda \geq 460 \mathrm{~nm})$ of the grey $\mathrm{H}_{2}-\mathrm{In}_{2} \mathrm{O}_{3} \cdot{ }^{38}$ In contrast $\mathrm{In}_{2} \mathrm{O}_{3}$ sample obtained from calcination in air shows yellow colour. 

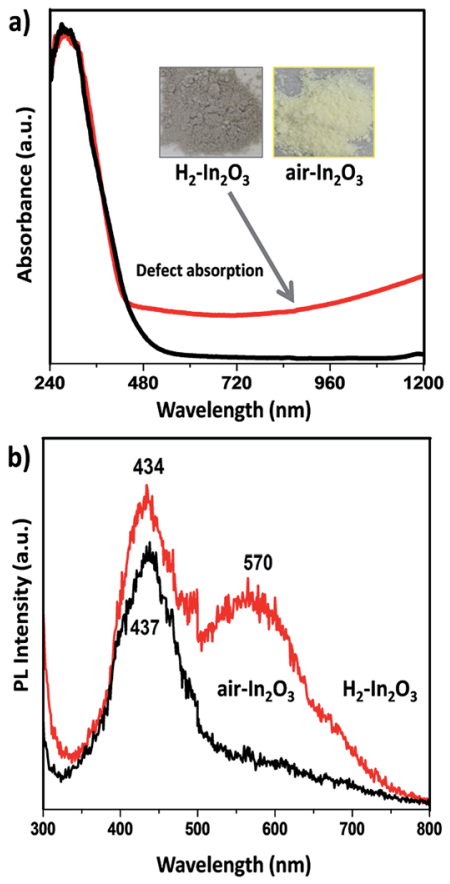

Fig. 2 (a) The UV-Vis-NIR absorption spectra of air- $\ln _{2} \mathrm{O}_{3}$ (black line) and $\mathrm{H}_{2}-\mathrm{In}_{2} \mathrm{O}_{3}$ (red line). The inset in (a) show the corresponding photographs. (b) Room temperature photoluminescence spectra of air- and $\mathrm{H}_{2}-\mathrm{In}_{2} \mathrm{O}_{3}$ (excited at $280 \mathrm{~nm}$ ).

Moreover, it can be seen from the spectra that both samples exhibit same absorption in UV range and absorption edges in visible region. In addition, it is worth mentioning that hydrogen treated sample is very stable in air because there was no colour change after keeping $\mathrm{H}_{2}-\mathrm{In}_{2} \mathrm{O}_{3}$ (grey colour) sample in air for two months.

We observed distinct fluorescent emission for $\mathrm{H}_{2}-\mathrm{In}_{2} \mathrm{O}_{3}$ under UV excitation from air- $\operatorname{In}_{2} \mathrm{O}_{3}(280 \mathrm{~nm}$, according to UV absorbance). As shown in Fig. 2b, both samples display similar strong emission band in blue region (400-500 $\mathrm{nm})$, centered at 434 and $437 \mathrm{~nm}$ for $\mathrm{H}_{2}-\mathrm{In}_{2} \mathrm{O}_{3}$ and air- $\mathrm{In}_{2} \mathrm{O}_{3}$, respectively. However, $\mathrm{H}_{2}$ $\mathrm{In}_{2} \mathrm{O}_{3}$ exhibits an additional wide band emission covering greenyellow region centered at $570 \mathrm{~nm}$. The blue emission peaks in both samples can be attributed to the expected oxygen vacancies generated during calcination process. It is well studied that with the transformation of crystalline phase from $\operatorname{In}(\mathrm{OH})_{3}$ to $\operatorname{In}_{2} \mathrm{O}_{3}$, the lattice oxygen can be removed in the form of water or $\mathrm{O}_{2}$, which in turn leads to the formation of shallow energy levels (oxygen vacancies) in the band structure. ${ }^{39}$ As discussed above, fluorescent emissions of $\operatorname{In}_{2} \mathrm{O}_{3}$ samples are dominated by their band energy levels, electronic and defect states etc. Therefore, we applied various spectroscopic technologies to study the origin of green-yellow emission and how hydrogen treatment changed the intrinsic states of $\mathrm{In}_{2} \mathrm{O}_{3}$.

The intrinsic structural changes of as prepared samples treated in air and hydrogen environment were analysed via Raman scattering spectra, as shown in Fig. 3a. The room temperature Raman spectra of both samples exhibited a low frequency set at $130 \mathrm{~cm}^{-1}$ (In-O vibration), two frequencies
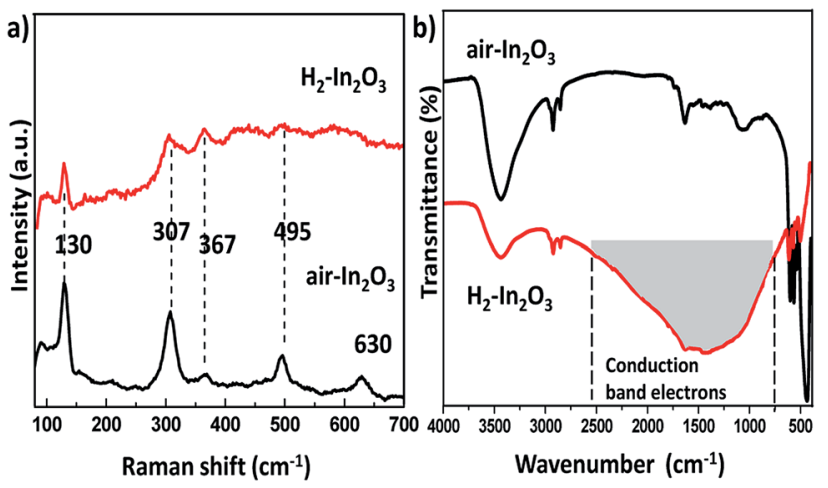

Fig. 3 (a) Room temperature Raman spectra of air- $\ln _{2} \mathrm{O}_{3}$ and $\mathrm{H}_{2}$ $\mathrm{In}_{2} \mathrm{O}_{3}$. (b) FT-IR spectra of air- and $\mathrm{H}_{2}-\ln _{2} \mathrm{O}_{3}$.

traced at 307 and $367 \mathrm{~cm}^{-1}$ (stretching vibrations of In-O-In). Two high frequencies located at 495 and $630 \mathrm{~cm}^{-1}$ belong to the typical vibration modes of bcc- $\operatorname{In}_{2} \mathrm{O}_{3}$, which are in good agreement with reported values in the literature. ${ }^{\mathbf{4 0 - 4 3}}$ Nevertheless, $\mathrm{H}_{2}-\mathrm{In}_{2} \mathrm{O}_{3}$ shows much lower intensity, which reveals that hydrogen treatment increases the disorderliness of $\operatorname{In}_{2} \mathrm{O}_{3}$ as comparing with air- $\operatorname{In}_{2} \mathrm{O}_{3}$. Meanwhile, hydrogen treated sample induces a very characteristic broad absorption in a range of 700$2800 \mathrm{~cm}^{-1}$ in IR spectrum, as represented in grey area in Fig. 3b. This featureless absorption is attributed to hydrogen induced changes of the CB and shallow donor state (DS) electron concentration in nonstoichiometric n-type semiconducting oxides. ${ }^{32,44-46}$

Hydrogen treatment on $\operatorname{In}_{2} \mathrm{O}_{3}$ may yield different defects, such as substitutional hydrogen at oxygen site and interstitial hydrogen at anti-bonding position. And these defects are shallow, which slightly overlap the bottom of the conduction band (CB). ${ }^{34}$ Regardless its specific position within the lattice, hydrogen donate electrons to the host material and creates defects, thereby populating both $\mathrm{CB}$ and shallow levels. ${ }^{34}$ According to the FT-IR analysis hydrogen treatment governed the defects, which in turn serves as electron donor states within the band gap of $\mathrm{H}_{2}-\mathrm{In}_{2} \mathrm{O}_{3}$ (see more detail in ESI $\dagger$ ). The other hydrogen generated defects are oxygen vacancies. From the UV measurements it can be speculated that oxygen vacancies induced large number of defects in $\mathrm{H}_{2}-\mathrm{In}_{2} \mathrm{O}_{3}$. These oxygen vacancies are assumed to be the recombination centres for the PL processes.

In order to further investigate the nature of oxygen vacancies, we have measured room temperature electron paramagnetic resonance (EPR) spectroscopy. The EPR spectra of $\mathrm{H}_{2}-\mathrm{In}_{2} \mathrm{O}_{3}$ (Fig. 4a) exhibit a sharp and intense signal at $g=2.00$, which shows that hydrogen treated sample possess paramagnetic centres (singly ionized oxygen vacancies). In contrast, the air$\mathrm{In}_{2} \mathrm{O}_{3}$ is antiferromagnetic and indicates complete absence of EPR signal. EPR analysis was also performed under $\mathrm{N}_{2}$ atmosphere for comparison (Fig. 4b). Because the EPR signals and intensities are sensitive to atmospheric oxygen. ${ }^{47}$ It can be clearly seen that the EPR signals are almost identical as measured in air and $\mathrm{N}_{2}$ atmosphere. This further confirms that 

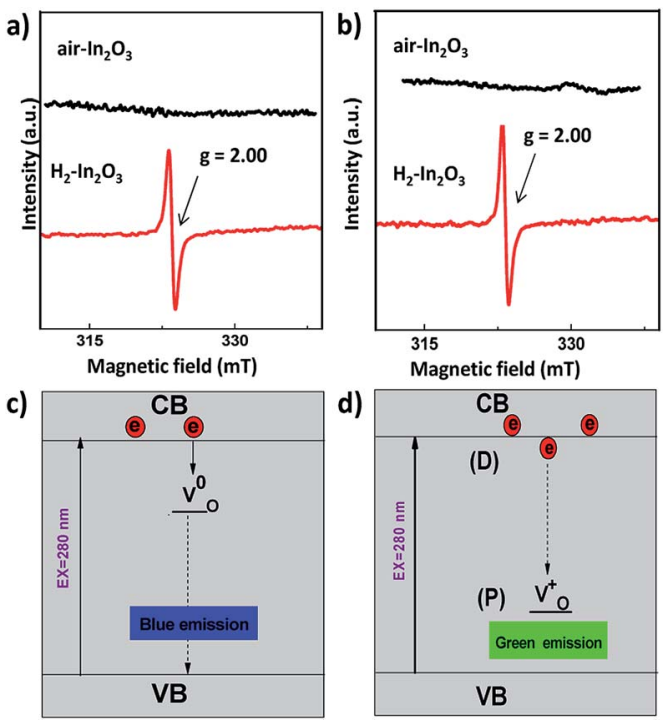

Fig. 4 (a) EPR spectra of air- and $\mathrm{H}_{2}-\ln _{2} \mathrm{O}_{3}$ at room temperature. (b) EPR spectra of air- $-\mathrm{n}_{2} \mathrm{O}_{3}$ and $\mathrm{H}_{2}-\mathrm{In}_{2} \mathrm{O}_{3}$ in $\mathrm{N}_{2}$ atmosphere. Simple schematic model for (c) blue emission in air- and $\mathrm{H}_{2}-\ln _{2} \mathrm{O}_{3}$ (d) donor (D) and passivation (P) originated PL emissions in $\mathrm{H}_{2}-\mathrm{In}_{2} \mathrm{O}_{3}$. Solid black arrows show non-radioactive transitions and dashed black arrows indicate radiative transitions.

EPR signal comes from $\mathrm{H}_{2}-\operatorname{In}_{2} \mathrm{O}_{3}$ sample itself due to hydrogen treatment. The existence of EPR signals at $g=2.00$ are generally considered as a signature of singly ionized oxygen vacancies $\left(\mathrm{V}_{\mathrm{O}}^{+}\right.$, passivation centres) and anticipated as recombination centres for the PL processes. ${ }^{48}$

PL emissions are often used to determine the efficiency of charge carrier transfer and trapping, as well as to examine the lifetime of photo-induced $\mathrm{e}^{-}$and $\mathrm{h}^{+}$pairs in semiconductor. Therefore, we performed photocatalytic methyl orange degradation test over both air- and $\mathrm{H}_{2}-\mathrm{In}_{2} \mathrm{O}_{3}$ in order to examine the effect of PL on the photocatalytic activity (Fig. S4 $\dagger$ ). The results clearly shows that $\mathrm{H}_{2}-\mathrm{In}_{2} \mathrm{O}_{3}$ gives rise to lower photo-catalytic activity in comparison with air- $\operatorname{In}_{2} \mathrm{O}_{3}$. This agrees with that $\mathrm{V}_{\mathrm{O}}^{+}$(passivation centres) in $\mathrm{H}_{2}-\mathrm{In}_{2} \mathrm{O}_{3}$ acts as mid gap radiative recombination centres and traps photo-induced electrons. This recombination process leads to decrease the photocatalytic activity of $\mathrm{H}_{2}-\mathrm{In}_{2} \mathrm{O}_{3}$.

Our attribution of green-yellow PL emission to the shallow donors to the deep holes at oxygen vacancies does not work against the view of green photoemission originating from the defects. In this work we show a reasonable correlation between green-yellow PL emission, paramagnetic oxygen vacancy (passivation center) and CB electrons (donor behavior), as shown in Fig. 4c and d. Grey coloration and EPR data both clarify the presence of oxygen vacancies $\left(\mathrm{V}_{\mathrm{O}}^{+}\right)$. Whereas, FT-IR spectra reveals that due to hydrogen-induced defects, both delocalized (within $\mathrm{CB}$ ) and localized (below $\mathrm{CB}$ ) electrons exist in $\mathrm{H}_{2}-\mathrm{In}_{2} \mathrm{O}_{3}$. In this scenario, upon UV excitation a photoinduced carrier (shallow state electron) readily combines with the hole in $\mathrm{V}_{\mathrm{O}}^{+}$via radiative recombination process and emits green-yellow PL emission in $\mathrm{H}_{2}-\operatorname{In}_{2} \mathrm{O}_{3}$.

\section{Conclusion}

We synthesized $\mathrm{In}_{2} \mathrm{O}_{3}$ nanoparticles by hydrothermal process followed with subsequent heat treatment in air and under hydrogen atmosphere. Structural, optical and luminescence properties of $\mathrm{H}_{2}-\mathrm{In}_{2} \mathrm{O}_{3}$ has been demonstrated herein. We observe that hydrogen treatment has no influence on the crystal structure, but alter intrinsic electronic structure and optical properties. $\mathrm{H}_{2}-\mathrm{In}_{2} \mathrm{O}_{3}$ generates photoemission ranging from blue to green-yellow, while air- $\operatorname{In}_{2} \mathrm{O}_{3}$ shows only blue emission. In $\mathrm{H}_{2}-\mathrm{In}_{2} \mathrm{O}_{3}$ the defect related green-yellow (500-650 nm) emission reveals the transition of photo-induced electrons to the holes in $\mathrm{V}_{\mathrm{O}}^{+}$. EPR, FT-IR and UV spectroscopies provide indisputable evidences that $\mathrm{H}_{2}-\mathrm{In}_{2} \mathrm{O}_{3}$ contains large number of defects. This work has demonstrated that hydrogen treatment can be used as a promising strategy to fundamentally alter the PL emission performance of $\operatorname{In}_{2} \mathrm{O}_{3}$.

\section{Experimental}

The $\operatorname{In}_{2} \mathrm{O}_{3}$ samples were synthesized in the following procedure.

Firstly indium acetate tetrahydrate $(0.2 \mathrm{M})$ was added into ethanol/deionized water $(14 / 2 \mathrm{ml})$ and stirred for $2 \mathrm{~h}$. After stirring, the mixture was transferred into a $25 \mathrm{ml}$ Teflon-line stainless steel autoclave and heated at $150{ }^{\circ} \mathrm{C}$ for $24 \mathrm{~h}$. Reaction autoclave was cooled to room temperature naturally and then white powder of indium hydroxide was obtained after several cycles of washing and centrifuging. The prepared powder was oven-dried at $90{ }^{\circ} \mathrm{C}$ for $12 \mathrm{~h}$. The conversion of indium hydroxide to indium oxide was carried out in a tubular furnace in air at $400{ }^{\circ} \mathrm{C}$ for $12 \mathrm{~h}$. For hydrogen treatment, reducing gas $\left(\mathrm{H}_{2} / \mathrm{Ar}, \mathrm{v} / \mathrm{v}=5 / 95\right)$ was introduced into the vertical quartz tube to purge air prior to heating. Afterward, hydrogen treatment was performed at $400{ }^{\circ} \mathrm{C}$ for $12 \mathrm{~h}$.

\subsection{Characterization}

The as-synthesized samples were analysed and characterized by X-ray powder diffraction (XRD), using a Rigaku MiniFlex $600 \mathrm{X}$ ray diffractometer with $\mathrm{Cu} \mathrm{K} \alpha(\lambda=1.54178 \AA)$. Scanning electron microscopy (Zeiss Supra 40 scanning electron microscope at an acceleration voltage of $5 \mathrm{kV}$ ) was used to detect the morphologies of the materials. Fourier transform infrared (FTIR) spectra of samples were examined on a SHIMADZU IR Affinity-1 spectrometer using $\mathrm{KBr}$ pellet. Raman spectra were recorded with LABRAM-HR spectrometer. XPS was recorded on ESCALab MKII Photoelectron spectrometer. Electron paramagnetic resonance (EPR) measurement was performed by JESFA2OO spectrometer (JEOL) at room temperature. Solid state UV-Vis-NIR spectra were collected using DUV-3700 UV-Vis spectrometer. For the investigation of photoluminescence properties the PL spectra was recorded at room temperature on Horiba JY Fluorolog-3-tau fluorescence spectrometer with a Xe lamp using excitation at $280 \mathrm{~nm}$. 


\subsection{Photocatalytic MO degradation}

Under exterior irradiation (cut $400 \mathrm{~nm}$, optical power density $150 \mathrm{~mW} \mathrm{~cm}^{-2}$ ) for certain period of time, the photocatalytic activities (at room temperature) of both samples (air- and $\mathrm{H}_{2}$ $\mathrm{In}_{2} \mathrm{O}_{3}$ ) are evaluated from photocatalytic degradation of methyl orange (MO). The contents of MO at certain time intervals could be monitored by (absorption peak at $\lambda=464$ ) using UV-Vis spectrophotometer (TU-1810).

\section{Conflicts of interest}

There are no conflicts of interest to declare.

\section{Acknowledgements}

S. A. thanks for China scholarship council (CSC) for financial support. We sincerely acknowledge financial support from National Natural Science Foundation of China (NSFC, 21571167, 51502282), Chinese Academy of Sciences, the fundamental Research Funds for the Central universities (WK2060190053) and Anhui Province Natural Science Foundation (1608085MB28).

\section{References}

1 H. Yang, L. Liu, H. Liang, J. Wei and Y. Yang, CrystEngComm, 2011, 13, 5011-5501.

2 T. S. Ko, C. P. Chu, J. R. Chen, Y. A. Chang, T. C. Lu, H. C. Kuo and S. C. Wang, J. Vac. Sci. Technol., A, 2007, 25, 1038-1041.

3 C.-H. Chan, M.-H. Lin, L.-C. Chao, K.-Y. Lee, L.-C. Tien and C.-H. Ho, J. Phys. Chem. C, 2016, 120, 21983-21989.

4 W. Yin, J. Su, M. Cao, C. Ni, C. Hu and B. Wei, J. Phys. Chem. $C, 2010,114,65-73$.

5 J. Yang, C. Lin, Z. Wang and J. Lin, Inorg. Chem., 2006, 45, 8973-8979.

6 C. Liang, G. Meng, Y. Lei, F. Phillipp and L. Zhang, Adv. Mater., 2001, 13, 1330-1333.

7 Q. Tang, W. Zhou, W. Zhang, S. Ou, K. Jiang, W. Yu and Y. Qian, Cryst. Growth Des., 2005, 5, 147-150.

8 X. S. Peng, G. W. Meng, J. Zhang, X. F. Wang, Y. W. Wang, C. Z. Wang and L. D. Zhang, J. Mater. Chem., 2002, 12, 1602-1605.

9 Z. Lin, Q. Zhu, Y. Dong, S. Liu, J.-G. Li, X. Li, D. Huo, M. Zhang, M. Xie and X. Sun, CrystEngComm, 2016, 18, 3768-3776.

10 A. Singhal, D. Jain, M. R. Pai, S. Agouram, D. Errandonea and A. k. Tyagi, RSC Adv., 2016, 6, 108393-108403.

11 Z. Guo, J. liu, Y. Jia, X. Chen, F. Meng, M. Li and J. Liu, Nanotechnology, 2008, 19, 345704.

12 P. Guha, S. Kar and S. Chaudhuri, Appl. Phys. Lett., 2004, 85, 3851-3853.

13 M. J. Zheng, L. D. Zhang, G. H. Li, X. Y. Zhang and X. F. Wang, Appl. Phys. Lett., 2001, 79, 839-841.

14 M. Jothibas, C. Manoharan, S. J. Jeyakumar and P. Praveen, J. Mater. Sci.: Mater. Electron., 2015, 26, 9600-9606.
15 D. Yu, S.-H. Yu, S. Zhang, J. Zuo, D. Wang and Y. Qian, Adv. Funct. Mater., 2003, 13, 497-501.

16 W. Yin, D. V. Esposito, S. Yang, C. Ni, J. G. Chen, G. Zhao, Z. Zhang, C. Hu, M. Cao and B. Wei, J. Phys. Chem. C, 2010, 114, 13234-13240.

17 H. Cao, X. Qiu, Y. Liang and Q. Zhu, Appl. Phys. Lett., 2003, 83, 761-763.

18 C. Wang, D. Chen, X. Jiao and C. Chen, J. Phys. Chem. C, 2007, 111, 13398-13403.

19 S.-T. Jean and Y.-C. Her, Cryst. Growth Des., 2010, 10, 21042110.

20 C. Zhang and J. Lin, Chem. Soc. Rev., 2012, 41, 7938-7961.

21 M. Kumar, V. N. Sing, F. Singh, K. V. Lakshmi, B. R. Mehta and J. P. Singh, Appl. Phys. Lett., 2008, 92, 171907.

22 D. Liu, Y. Lv, M. Zhang, Y. Liu, Y. Zhu, R. Zong and Y. Zhu, J. Mater. Chem. A, 2014, 2, 15377-15388.

23 D. Shao, M. Yu, J. Lian and S. Sawyer, Appl. Phys. Lett., 2012, 101, 211103.

24 G. Wang, H. Wang, Y. Ling, Y. Tang, X. Yang, R. C. Fitzmorris, C. Wang, J. Z. Zhang and Y. Li, Nano Lett., 2011, 11, 3026-3033.

25 W. Zhou, W. Li, J.-Q. Wang, Y. Qu, Y. Yang, Y. Xie, K. Zhang, L. Wang, H. Fu and D. Zhao, J. Am. Chem. Soc., 2014, 136, 9280-9283.

26 X. Chen, L. Liu, P. Y. Yu and S. S. Mao, Science, 2011, 331, 746-750.

27 C. G. Van de Walle and J. Neugebauer, Nature, 2003, 423, 626-628.

28 M. Kumar, R. Chatterjee, S. Milikisiyants, A. Kanjilal, M. Voelskow, D. Grambole, K. V. Lakshmi and J. P. Sigh, Appl. Phys. Lett., 2009, 95, 013102.

29 T. Wang and P. V. Radovanovic, Chem. Commun., 2011, 47, 7161-7163.

30 N. Ohashi, T. Ishigaki, N. Okada, T. Sekiguchi, I. Sakaguchi and H. Haneda, Appl. Phys. Lett., 2002, 80, 2869-2871.

31 T. Sekiguchi, N. Ohashi and Y. Terada, Jpn. J. Appl. Phys., 1997, 36, L289.

32 D. A. Panayotov, S. P. Burrows and J. R. Morris, J. Phys. Chem. C, 2012, 116, 4535-4544.

33 H. Sezen, M. Buchholz, A. Nefedov, C. Natzeck, S. Heissler, C. Di Valentin and C. Wöll, Sci. Rep., 2014, 4, 3808.

34 J. J. Meléndez and M. Wierzbowska, J. Phys. Chem. C, 2016, 120, 4007-4015.

35 C. Shifu, Y. Xiaoling, Z. Huaye and L. Wei, J. Hazard. Mater., 2010, 180, 735-740.

36 T. Xia, P. Wallenmeyer, A. Anderson, J. Murowchick, L. Liu and X. Chen, RSC Adv., 2014, 4, 4154-41658.

37 A. Naldoni, M. Allieta, S. Santangelo, M. Marelli, F. Fabbri, S. Cappelli, C. L. Bianchi, R. Psaro and V. D. Santo, J. Am. Chem. Soc., 2012, 134, 7600-7603.

38 Q. Zhu, Y. Peng, L. Lin, C.-M. Fan, G.-Q. Gao, R.-X. Wang and A.-W. Xu, J. Mater. Chem. A, 2014, 2, 4429-4437.

39 J. Du, M. Yang, S. N. Cha, D. Rhen, M. Kang and D. J. Kang, Cryst. Growth Des., 2008, 8, 2312-2317.

40 O. M. Berengue, A. D. Rodrigues, C. J. Dalmaschio, A. J. Lanfredi, E. R. Leite and A. J. Chiquito, J. Phys. D: Appl. Phys., 2010, 43, 045401. 
41 H. Zhu, X. Wang, F. Yang and X. Yang, Cryst. Growth Des., 2008, 8, 950-956.

42 J. Gan, X. Lu, J. Wu, S. Xie, T. Zhai, M. Yu, Z. Zhang, Y. Mao, S. C. Wang, Y. Shen and Y. Tong, Sci. Rep., 2013, 3, 1021.

43 W. Yin, J. Su, M. Cao, C. Ni, S. G. Cloutier, Z. Huang, X. Ma, L. Ren, C. Hu and B. Wei, J. Phys. Chem. C, 2009, 113, 1949319499.

44 N. Siedl, P. Gügel and O. Diwald, J. Phys. Chem. C, 2013, 117, 20722-20729.
45 D. A. Panayotov and J. T. Yates Jr, Chem. Phys. Lett., 2007, 436, 204-208.

46 Y. Cao, X. Huang, Y. Wu, Y.-C. Zou, J. Zhao, G.-D. Li and X. Zou, RSC Adv., 2015, 5, 60541-60548.

47 X. Zou, J. Liu, J. Su, F. Zuo, J. Chen and P. Feng, Chem.-Eur. J., 2013, 19, 2866-2873.

48 W. Ji, M.-H. Lee, L. Hao, X. Xu, S. Agathopoulos, D. Zheng and C. Fang, Inorg. Chem., 2015, 54, 1556-1562. 